Article

\title{
The Influence of Multiple Specializations on Economic Performance in U.S. Metropolitan Areas
}

\author{
Saheum Hong ${ }^{1, *}$ and Yu Xiao ${ }^{2}$ \\ 1 Korea Research Institute for Human Settlements, 254 Simin-daero, Anyang-si 431-712, Korea \\ 2 Department of Landscape Architecture and Urban Planning, Texas A\&M University, 3137 TAMU, \\ College Station, TX 77843-3137, USA; yuxiao@tamu.edu \\ * Correspondence: saheum@krihs.re.kr; Tel.: +82-31-380-0356 \\ Academic Editor: Giuseppe Ioppolo \\ Received: 23 June 2016; Accepted: 14 September 2016; Published: 21 September 2016
}

\begin{abstract}
Scholars have recently been debating how economic structure affects regional economic performance. Regional economic structure typically indicates how the industries in regions are organized. The attribute of industrial organization in regions is typically measured by how the employment in a region is distributed among various sectors. If the employment in a region is highly concentrated on a limited number of sectors, that region is industrially specialized. On the contrary, when the employment is more evenly distributed among various industries, that region is highly diversified in its industrial organization. In this context, some researchers recognized that diversity and specialization are not opposite concepts. Instead, they can coexist, for example in the form of diversified specializations. In this study, this body of literature was extended by formulating an indicator to measure the extent of multiple specializations in regional economies and by examining the effect of multiple specializations on regional economic performance. Empirical analysis showed that specializing in multiple industrial pursuits helped regions to achieve both faster and more stable economic growth.
\end{abstract}

Keywords: economic structure; diversity; specialization; economic growth and stability

\section{Introduction}

Since Chinitz [1] suggested the possible linkage between regional economy and its economic structure, scholars have been debating how industrial structure affects regional economic performance [2-7]. Regional economic structure indicates the attributes of industrial organization in regions, which is typically measured by how the employment in a region is distributed among various industrial sectors. Specifically, if the employment in a region is highly concentrated on the limited number of sectors, that region is industrially specialized. On the contrary, when the employment is more evenly distributed among various industries, that region is highly diversified in its industrial organization. Most debates centered on whether regions should specialize or diversify their industrial mix in order to achieve high economic growth. According to the basic theory by Marshall [8], comparative advantages can drive economic growth in regions. Comparative advantage, which usually reflects regional differences in factor endowments, is also determined by specialized industrial sectors. In this context, the spatial concentration or specialization driven by agglomeration economies is regarded as an influential factor for urban growth [9]. Otherwise, in endogenous growth theory, a comparative advantage is also regarded as the result of innovative activities in regions. Innovation through cross-fertilization among various industries is recognized as the engine of regional economic growth [10]. In previous empirical studies, some found strong support of diversity in promoting growth [3,11], while others found evidence that supported industrial specialization [12-16]. Besides growth, this paper analyzed economic stability, which is known as another important aspect of 
regional economic performance related with industrial structure. Studies on industrial structure and stability usually found that industrial diversity increases economic stability [17-22]. Scant empirical research analyzed both stability and growth in the same context. Many questions still need to be answered, for instance: is an industrial structure good for growth also good for stability? Can growth and stability be achieved at the same time? What industrial structure supports both economic growth and stability in urban areas?

Moreover, many empirical studies utilized very simplistic indicators to measure industrial structure. Often, specialization and diversity were treated as exact opposites. One indicator was used to measure both specialization and diversity, assuming increasing in one means decreasing in the other [23-25]. In reality, being specialized does not mean lack of diversity. A region can specialize in multiple industrial pursuits, which is defined as multiple specializations by Malizia and Ke [20]. For instance, Houston, Texas was well known for its specialization in the oil and gas industry. Besides this main industry, Houston was also highly specialized in health care, transportation, and technology research and development. The Texas Medical Center, employing about 92,500 people with an annual budget of $\$ 14$ billion, was the largest medical institution in the world [26]. In 2012, the Port of Houston was ranked number one among all U.S. ports in both foreign tonnage and imports, bringing annually $\$ 264.9$ billion statewide economic impact [27]. Being the home of NASA's Johnson Space Center, Houston also played the role as an aerospace hub in the country. Malizia and Ke [20] hypothesized that specializing in more than one industrial sector can bring the benefits of specialization for growth and, at the same time, foster regional economic stability by compensating for one another when one sector is negatively affected by a shock. To date, to our knowledge, the concept of multiple specializations has been only formulated theoretically [20], and empirically measured in terms of the specializations of individual sectors. Thus, there is a need to collectively measure the multiple specializations and empirically test the effect of this measure.

This study is expected to contribute to the literature by formulating an indicator to empirically measure the extent of multiple specializations in regional economies and examine its effect on both growth and stability. The remainder of the paper is organized as follows. The next section summarizes the theoretical debates and empirical findings on industrial structure and regional economic performance. The new indicator is then introduced to measure multiple specializations. Following this, the research design, including data, variables, model specification and the analytical methods, is presented, which are followed by the discussion of the results from the empirical analysis. The last section concludes this study with discussions of policy implications and recommendations for future research.

\section{Effects of Economic Structure on Regional Economic Performance}

\subsection{Economic Structure and Growth}

There are two competing theories to explain the relationship between economic structure and growth. The major difference between these theories lies in how economic structure relates to innovation, which can catalyze endogenous economic growth in regions. Jacobs [10] stated that innovation arises primarily from the knowledge spillover across different industrial sectors. The transmission of complementary ideas across diverse sectors can promote research and development that lead to innovation and bring economic growth. In contrast, Marshall [8], Arrow [28] and Romer [29] argued that innovation comes from knowledge spillovers among firms in similar sectors. They claimed that knowledge spillovers are more likely to occur in a specialized economic structure because the knowledge accumulated by firms in a given industry can be more easily utilized by other firms in the same industrial sector. Similarly, Porter [30] also believed that the knowledge spillovers from a specialized economic structure promote economic growth in regions. Clustering, or similar firms being geographically close to each other, fosters knowledge spillovers and therefore, promotes regional economic growth [31]. 
Empirical studies yielded mixed and inconsistent results. Some researchers used diversity indicators to measure economic structure. Glaeser et al. [3] found that economic diversity in metro areas in the U.S. was positively associated with employment growth, while in another U.S.-based study, Attran [23] discovered a negative effect of diversity on per capita income growth at the state level. Moreover, Cingano and Schivardi [32] found a positive effect of diversity on employment growth at the regional level in Italy. A study from France found diversity to have different effects on various industrial sectors: diversity promotes employment growth in the service sector while stunts the growth of the manufacturing sector [33]. Three separate studies were conducted in the 1980s, 1990s and 2000s, to investigate the role of economic diversity on per capita income growth using similar industrial structural measures. Attran [23] showed a negative effect of diversity on per capita income growth in the 70s and 80s while Wagner and Deller [11], based on data from the 80s and 90s, found a positive impact of diversity. However, in the recent study, Izraeli and Murphy [25] could not observe any significant effect of economic diversity on per capita income growth.

Some researchers measured industrial structure by specialization indicators and the results are also mixed. Glaeser et al. [3] measured specialization using a location quotient, and showed a negative effect of specialization on employment growth. Similarly, it is revealed that regional industrial dominance of the manufacturing sector is negatively associated with employment growth in the U.S. metro areas [24]. In contrast, using a location quotient to measure specialization, Shuai [15] found that specialization has a positive effect on the employment growth of major sectors in Virginia. Henderson et al. [12] used an employment ratio to measure specialization, and Rosenthal and Strange [14] used the size of employment for measuring specialization. Both found positive effects of specialization on employment growth. Additionally, Drennan et al. [34] found that the positive effect of specialization on wage growth could be differently observed by time-period.

As we can see from the above, empirical results varied by geographical units of analysis, measures of economic structure, industrial sectors used in the analysis and the research time span. These mixed results imply that it is hard to determine the general relationship between the specific type of industrial structure and regional economic growth. Otherwise, there is a case that, by adjusting structural scale, a universal economic structure for growth can be derived [35].

\subsection{Economic Structure and Stability}

There is a general consensus in the theoretical understanding of how industrial structure affects economic stability. While regional industrial specialization may possibly reduce a region's flexibility to react to economic changing conditions [24], the diversity is generally believed to promote economic stability. According to McLaughlin [36], because industrial sectors in a region usually have different patterns of seasonal or cyclical fluctuations, the downturn of one sector can be compensated by the upturn of other sectors in the same region, resulting in low variation in regional economy. Thus, diversification of industrial mix can improve economic stability in regions.

Empirical studies largely supported the theoretical speculations. Most studies found positive effects of industrial diversity on enhancing regional economic stability, regardless of the types of diversity indicators and economic variables analyzed. For instance, diversity has been measured by normative indicators such as the national average index [37], the Ogive index [38-40] and the Entropy index $[17,20,21,23]$. Economic stability has been measured by unemployment rate $[17,20]$, fluctuations in employment and personal income [41,42] and more complicated indices such as the Regional Economic Instability indicator (REI) by Kort [19]. Nonetheless, these studies arrived at a consistent conclusion that economic diversity was positively associated with economic stability.

\subsection{Role of Multiple Specializations}

As a response to the simplistic treatment of diversity as lack of specialization, Malizia and Ke [20] pointed out that local and regional economy can be both specialized and diversified. They argued 
that diversity does not necessarily indicate the absence of specialization. The economic structure of multiple specializations can play a significant role in regional economic growth.

Specifically, the concept of multiple specializations captures diversity in specializations. In terms of economic growth, regions specialized in diversified industrial pursuits may benefit from the economies of scale of each of the specialized sectors and at the same time enjoy the economies of scope and positive externalities from cross-fertilization across diverse sectors. In terms of economic stability, the effects of severe fluctuations can be smoothed by the nature of diversity in these multiple specializations [43]. As mentioned above, regions with diversified specialized sectors might be more stable than those with a narrowly specialized structure because the different business cycles of diverse sectors can offset each other. In other words, successfully acquiring new specializations from different sectors is a very essential process to sustain economic growth by compensating the loss of declining sectors [16].

Therefore, regarding the role of multiple specializations, Malizia and Ke [20] (p. 223) asserted that "the specializations in multiple sectors can be the source of competitiveness for economic growth, as well as compensate for one another when fluctuations occur". Similarly, Farhauer and Kröll [44] (p. 68) stated that the "advantage of diversified-specialized cities is that the benefits of specialization can be enjoyed while, at the same time, the risks going along with a crisis-prone mono-structure are mitigated". In short, specializations in multiple industrial pursuits should allow the region to reap the benefits of specialization and at the same time reduce instability.

To our knowledge, no study has empirically measured multiple specializations in industrial structure and studied its effect on both economic growth and stability. In the next section, an empirical indicator is proposed to measure multiple specializations in regional economic structure.

\section{Measurement of Multiple Specializations}

\subsection{Measuring Multiple Specializations}

The development of the empirical measurement of multiple specializations starts from measuring specialization in each sector using a Location Quotient (LQ). The LQ indicates the portion of industry employment in a region relative to the national share of that industry. It is defined as:

$$
L Q_{n}=S_{n i} / N S_{n}
$$

where $S_{n i}$ is the employment share of sector $n$ in region $i$ and $N S_{n}$ is the employment share of sector $n$ at the national level.

The multiple specializations indicator (MSI) was constructed based on the LQs of sectors in a region. Two steps were involved: First, the total number of specialized sectors that had LQ values greater than the cut-off value was calculated in each region. Although the LQ value of one is generally regarded as the standard for classifying specialized industries, uniformly applying the cut-off value of one seemed to be too arbitrary. So, in order to consider the relative difference in the level of specialization by each industrial sector, different cut-off values were applied for each sector based on the distribution of LQs in that sector across all regions. The cut-off value was set as the 80th percentile LQ values for each industry. Industrial sectors with LQ higher than this cut-off value were classified as specialized. A few sectors, such as mining support activities, couriers and messengers, or air transportation, had a cut-off value below one. In these cases, we used one as the cut-off value.

Second, the MSI is derived by dividing this total number of specialized sectors by the total number of sectors with non-zero employment in the region. In other words, the MSI is the proportion of specialized sectors in a region. The MSI of region $i$ is calculated as:

$$
M S I_{i}=\frac{1}{N} \sum_{n=1}^{N} S P_{n}, \text { where } S P_{n} \begin{cases}=1 & \text { if } L Q_{n}>\text { cut }- \text { off value } \\ =0 & \text { otherwise }\end{cases}
$$


$L Q_{n}$ is the LQ of sector $n$ and $N$ is the total number of sectors in region $i$. The MSI converges to the maximum value of one if the LQs of all the sectors in a region are specialized. The MSI can take a minimum value of zero when there is no relatively specialized sector in that region.

\subsection{Comparing the MSI to Commonly-Used Diversity and Specialization Measures}

Before examining the effects of multiple specializations on economic performance, the MSI is first compared to the Entropy and Herfindahl indexes, which are the most frequently used measures for industrial diversity and specialization in the literature. The Entropy index is a type of normative indicator that measures economic structure using the distribution of the overall employment among all the sectors in a region [45]. The basic idea of this index was first developed by Theil and Finizza [46] and has been widely used in measuring the diversity level of overall economic structure (for example, it is used by Attran [23], Malizia and Ke [20] and Trendle [22]). The Entropy index is calculated by:

$$
\text { Entropy Index }=\sum_{n=1}^{N} S_{n} \ln \left(\frac{1}{S_{n}}\right)
$$

where $S_{n}$ is the absolute employment share of industry $n$ and $N$ is the total number of industries in Metropolitan Statistical Area (MSA) $i$. The value of the Entropy index increases as employment becomes more evenly distributed across sectors.

The Herfindahl index, introduced and developed by Herfindahl [47] and Hirschman [48], has been widely applied in the field of industrial economics to measure market concentration [49]. This index has also been used by researchers (for example, Drucker [24], Izraeli and Murphy [25] and Mizuno et al. [50]) to measure the level of specialization. The Herfindahl index is defined as:

$$
\text { Herfindahl Index }=\sum_{n=1}^{N} S_{n}^{2}
$$

where $S_{n}$ is the absolute employment share of industry $n$ and $N$ is the total number of industries in MSA $i$. Unlike the Entropy index, the value of the Herfindahl index increases as employment becomes more concentrated in the limited number of sectors.

Empirical data was used to examine the relationship between the MSI and Entropy/Herfindahl index. We first calculated the MSI, Entropy and Herfindahl indexes using employment data from all Metropolitan Areas in the U.S. in 1998. Then, we plotted the MSI with Entropy and the MSI with Herfindahl on scatterplots. Figure 1 shows the scatterplot of the MSI and Entropy index. The red line shows the fitted simple linear regression using the ordinary least square method. Figure 2 shows the scatterplot of the MSI and Herfindahl index, also with fitted linear regression line.

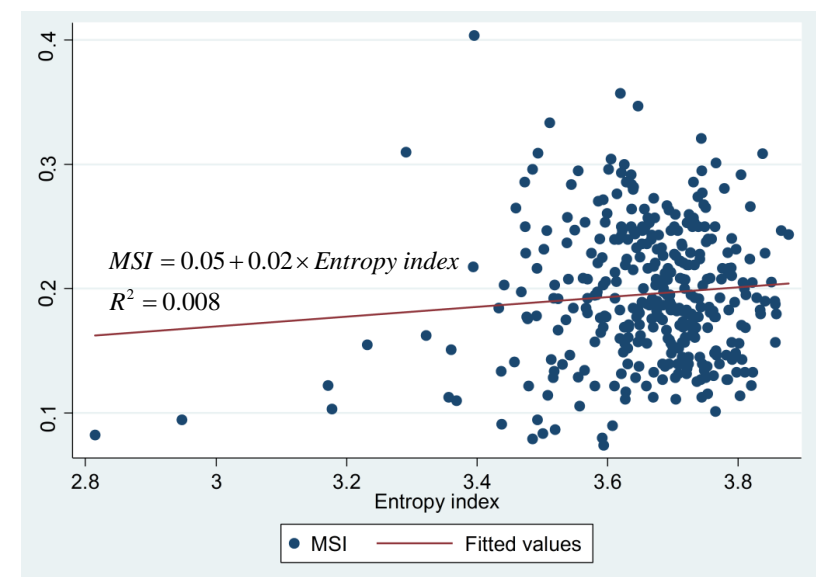

Figure 1. Multiple specializations indicator (MSI) and Entropy index. 


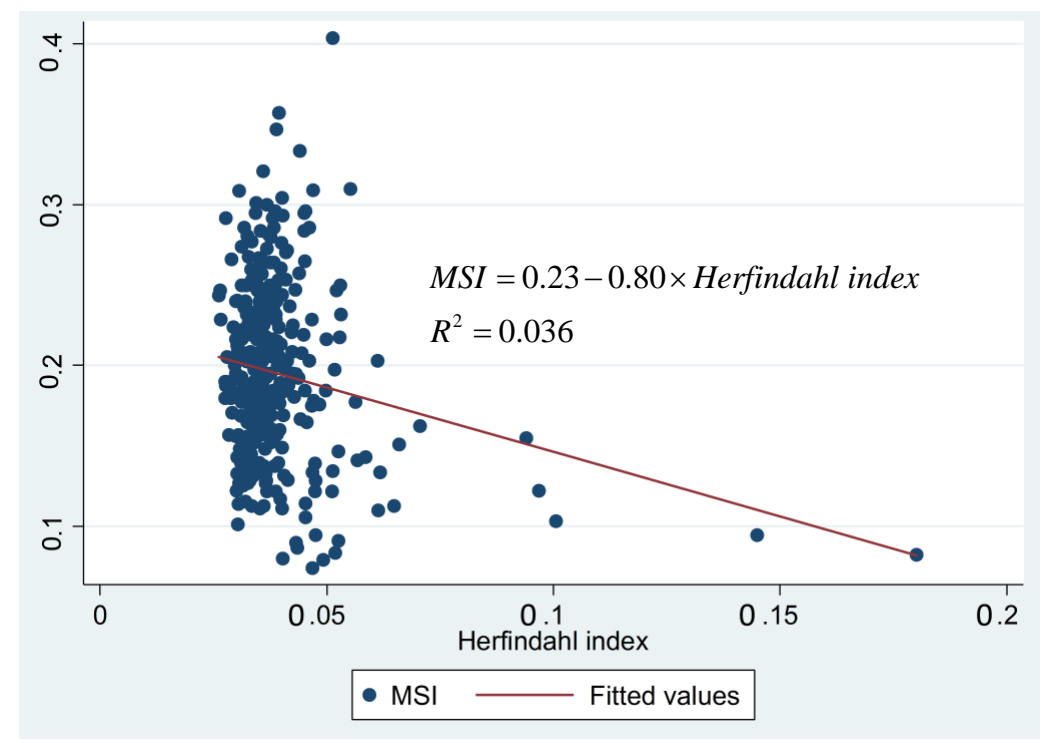

Figure 2. MSI and Herfindahl index.

As we can see, the goodness of fit of the predicted lines on Figures 1 and 2 were both quite low. The Entropy index can only explain 0.8 percent of variations in the MSI, while the Herfindahl index can explain 3.6 percent of variations in the MSI. Moreover, the scatterplot suggested that the negative relationship between the MSI and Herfindahl index might be highly influenced by a few extreme values of the Herfindahl index. Furthermore, Table 1 shows the series of correlations between the MSI and other two indexes for every three years during the study period. As indicated in the table, for most years, even if the MSI is significantly related with these indexes, the levels of correlations were quite low. Therefore, by combing these results, it can be implied that the MSI measures a facet of regional economic structure that is different from the commonly-used Entropy and Herfindahl indexes.

Table 1. Series of correlation coefficients between MSI and Entropy/Herfindahl index.

\begin{tabular}{cccccc}
\hline & $\mathbf{1 9 9 8}$ & $\mathbf{2 0 0 1}$ & $\mathbf{2 0 0 4}$ & $\mathbf{2 0 0 7}$ & $\mathbf{2 0 1 0}$ \\
\hline \multirow{2}{*}{ Entropy } & 0.099 & 0.169 & 0.112 & 0.152 & 0.160 \\
& $(0.06)$ & $(0.00)$ & $(0.04)$ & $(0.00)$ & $(0.00)$ \\
\hline \multirow{2}{*}{ Herfindahl } & -0.191 & -0.253 & -0.204 & -0.217 & -0.213 \\
& $(0.00)$ & $(0.00)$ & $(0.00)$ & $(0.00)$ & $(0.00)$ \\
\hline
\end{tabular}

Note: The values in the parentheses indicate the $p$-values.

It should be pointed out that the MSI is used not to replace the commonly-used diversity measures in empirical analysis, but rather to complement them. Because the MSI measures only the extent of diversification in specializations, it does not capture the overall diversity or specialization in the economic structure. Hence, the MSI should be used in conjunction with other measures to capture the full picture of the economic structure.

Another caveat is that because the MSI is calculated from the LQs of industries in a region, it inherited the same limitations of LQ such as being sensitive to the size of employment in regions [51]. For instance, the MSI of a small region can be overestimated because sectors can be more easily categorized as specialized ones although they have quite small employment sizes. Hence, when estimating the effect of the MSI, one should control for the size of the region's economy. 


\section{Data and Empirical Framework}

This study empirically investigated the effect of economic structure on the speed and stability of employment growth of the 353 MSAs in the lower contiguous 48 states from 1998 to 2010. The County Business Patterns (CBP), the main dataset used to construct economic structural indicators in this study, switched from the Standard Industrial Classification (SIC) to the North America Industry Classification System (NAICS) in 1998. Therefore, for consistency in industrial classifications, only the data after 1998 was examined. Economic performance was measured by both employment growth and stability. Additionally, wage growth was also employed to address the issue of "growth without jobs". Data on these employment and wage performance indicators were from the Quarterly Census of Employment and Wages (QCEW) published by the Bureau of Labor Statistics (BLS). The following two regression models were estimated:

Growth model:

$$
\begin{aligned}
E G= & \beta_{0}+\beta_{1} M S I+\beta_{2} \text { Entropy }+\beta_{3} C O M P \\
& +\beta_{4} M A N U+\beta_{5} E D H+\beta_{6} E D U C+\beta_{7} \ln (P O P) \\
& +\beta_{8} \text { preEG }+\beta_{9} \ln (\text { preINSTAB })+\beta_{10} M W+\beta_{11} N E+\beta_{12} S+\varepsilon
\end{aligned}
$$

Instability model:

$$
\begin{aligned}
& \ln (\text { INSTAB })=\beta_{0}+\beta_{1} M S I+\beta_{2} \text { Entropy }+\beta_{3} \text { COMP } \\
& \quad+\beta_{4} M A N U+\beta_{5} E D H+\beta_{6} \text { EDUC }+\beta_{7} \ln (P O P) \\
& \quad+\beta_{8} \text { preEG }+\beta_{9} \ln (\text { preINSTAB })+\beta_{10} M W+\beta_{11} N E+\beta_{12} S+\varepsilon
\end{aligned}
$$

\subsection{Depedent Variables}

For the growth model, economic growth, $E G$, is measured by the average annual employment growth rate:

$$
E G=\frac{\sum_{t=2}^{T}\left[100 \times \frac{E_{i t}-E_{i t-1}}{E_{i t-1}}\right]}{T-1}
$$

where $E_{i t}$ is the employment level in MSA $i$ at year $t$ and $T$ is the number of total years. For wage growth, the average annual wage growth rate is also employed by the same manner.

In the instability model, economic instability, INSTAB, is measured by the average deviation from the employment trend, divided by trend employment (the same as in Kort's [19] Regional Economic Instability indicator (REI)). The value of the INSTAB index increases as the difference between the actual and predicted employment increases. In this study, this measure was calculated using monthly employment data during the research time span from 1998 to 2010:

$$
\operatorname{INSTAB}=\left\{\frac{\sum_{t=1}^{T}\left[\left(E_{i t}-E_{i t}^{T r}\right) / E_{i t}^{T r}\right]^{2}}{T}\right\}^{0.5}
$$

where $E_{i t}$ is the employment level in MSA $i$ at month $t, E_{i t}^{T r}$ is the predicted employment level from trend regression in MSA $i$ at month $t$ and $T$ is the total number of months. Because the distribution of INSTAB showed skewness, the logged value of instability indicator was used in the empirical models.

Furthermore, an issue can arise where these two performance variables might be overlapped with each other when measuring the economic performance in regions. Specifically, when there is a drastic employment increase, the employment level of that region should experience a large variation caused by this, which can be observed as some type of economic instability. In order to address this issue, the correlation analysis between these variables was conducted first. The correlation coefficient 
is about 0.23 , reflecting the fact that economic growth could accompany some economic variation. However, the fairly small value of the coefficient shows that they still measure the different outcomes of regional economic performance.

\subsection{Independent Variables}

Economic structure indicators: The economic structure was measured by the MSI and Entropy index. As discussed earlier, the MSI complements other commonly-used measures of diversification and specialization. Hence, both the MSI and Entropy index were used to measure economic structure. Both the MSI and Entropy were calculated based on the 3-digit level industries of NAICS, using the County Business Patterns data. In 1998, the 3-digit level industries of NAICS was composed of 83 industrial sectors.

Competition: Competition is one of the important factors that can influence both growth and stability. Both Jacobs [10] and Porter [30] believed that a high level of competition can stimulate firms to develop and adopt innovative ideas, thus, promoting economic growth. In terms of stability, according to Gaspar and Massa [52], severe fluctuation can be smoothed by a hedge effect based on a few firms that have strong market power in less competitive conditions. So, in this study, we included a competition indicator that was previous used by Glaeser et al. [3]. The competition level of industry $n$ is defined as:

$$
\operatorname{COMP}_{n}=\frac{f_{n i} / e_{n i}}{F_{n} / E_{n}}
$$

where $f_{n i}$ is the number of firms in industry $n$ in region $i, e_{n i}$ is the employment of industry $n$ in region $i, F_{n}$ is the total number of firms in industry $n$ at the national level and $E_{n}$ is the total employment of industry $n$ at the national level. Finally, the overall level of competition for each MSA (COMP) was measured by the weighted average of competition indicators for all 3-digit level NAICS industries in MSAs.

Performance of individual sectors: Regional economies can also be heavily influenced by the performance of a few specific sectors [53]. To control for the effect from the performance of individual sectors, the set of independent variables included the average annual growth rates of the sectors that grew or declined the most during the research time period from 1998 to 2010. The fastest growing sector was education and health services $(E D H)$ and the fastest declining sector was manufacturing $(M A N U)$.

Educational attainment: The accumulation of human capital can contribute to regional economic growth because an educated work force is more productive than a less educated one [54]. Regions with more human capital can enjoy higher levels of economic stability because the jobs requiring a more educated or skilled labor force are less likely to be affected by layoffs. The percentage of population 25 years or older with at least a bachelor's degree in the MSAs was used as a measurement of educational attainment (EDUC).

Population size: The population size might affect economic performance in regions in various ways. For instance, the agglomeration of economies based on large population size can also attract more firms or industries into a region and hence contribute to economic growth [55]. In addition, as discussed in a previous section, the MSI is sensitive to population size. We used the logged value of population size at the initial time point 1998 to control for the size effect (POP).

Lagged economic performance: We used the employment growth rate and instability for the past five years (1993-1997) prior to this study period as the control variables to examine the effect of time dependency of the economic performance in regions.

Regional dummy variables: This study included three regional dummy variables ( $M W, N E$ and $S$, excluding the West region)) based on four Census regions to control for the effects of the geographical locations of the MSAs. This is because the indigenous geographical factors such as climate or historical background, which are shared by the MSAs located in the same geographical regions, might affect economic performance [56].

Table 2 shows the description and sources of variables used in the analysis. 
Table 2. Description and sources of variables.

\begin{tabular}{|c|c|c|c|}
\hline Category & Symbol & Description & Data Source \\
\hline \multirow{3}{*}{$\begin{array}{l}\text { Dependent } \\
\text { Variables }\end{array}$} & EG & $\begin{array}{l}\text { Average annual employment growth rates (\%), } \\
\text { 1998-2010 }\end{array}$ & BLS \\
\hline & W_EG & Average annual wage growth rates (\%), 1998-2010 & BLS \\
\hline & INSTAB & $\begin{array}{l}\text { Average deviation between actual employment and } \\
\text { predicted employment trends from a given time and } \\
\text { divided by this predicted employment, 1998-2010 }\end{array}$ & BLS \\
\hline \multirow{2}{*}{$\begin{array}{l}\text { Independent } \\
\text { Variables }\end{array}$} & MSI & $\begin{array}{l}\text { The proportion of sectors in an economy with an LQ } \\
\text { value larger than the cut-off value, } 1998\end{array}$ & СВР \\
\hline & Entropy & $\begin{array}{l}\text { Measuring the diversity of economic structure using the } \\
\text { Entropy index, } 1998\end{array}$ & $\mathrm{CBP}$ \\
\hline \multirow{8}{*}{$\begin{array}{l}\text { Control } \\
\text { Variables }\end{array}$} & COMP & $\begin{array}{l}\text { Weighted average of competition indicators of 3-digit } \\
\text { industries, } 1998\end{array}$ & СBP \\
\hline & EDUC & $\begin{array}{l}\text { Percentage of population } 25 \text { years or older with at least a } \\
\text { bachelor's degree, } 1998\end{array}$ & Census \\
\hline & POP & Population size at the initial time points (logged), 1998 & BLS \\
\hline & MANU & $\begin{array}{l}\text { Average annual growth rate of Manufacturing sector, } \\
\text { 1998-2010 }\end{array}$ & \multirow{2}{*}{ CBP } \\
\hline & $\mathrm{EDH}$ & $\begin{array}{l}\text { Average annual growth rate of Education and Health } \\
\text { Service sector, 1998-2010 }\end{array}$ & \\
\hline & MW, NE, S & $\begin{array}{l}\text { Three dummy variables for Census regions Midwest, } \\
\text { Northeast, and South, } 1998\end{array}$ & Census \\
\hline & PreEG & $\begin{array}{l}\text { Average of annual employment growth rates (\%) during } \\
\text { the last } 5 \text { years, 1993-1998 }\end{array}$ & \multirow{2}{*}{ BLS } \\
\hline & PreINSTAB & $\begin{array}{l}\text { Level of instability indicator for monthly employment } \\
\text { during the last } 5 \text { years, 1993-1998 }\end{array}$ & \\
\hline
\end{tabular}

Note: CBP stands for County Business Pattern; BLS stands for Bureau of Labor Statistics.

\section{Regression Results}

To compare models with and without the multiple specialization measure, two sets of models were estimated: one follows the typical setup of similar models found in the literature, using the Entropy index to capture the diversity or lack of specialization in the regional industrial structure. The second set of models added the MSI to examine the effects of multiple specializations on economic performance.

Because spatial autocorrelation was found in the residuals from the ordinary least square models, in order to control for the spatial effects, the spatial lag models for both growth and instability were estimated. Additionally, the serious issue of leverage was not found in all estimation results.

\subsection{Growth Models}

Models 1 and 2 in Table 3 presented the estimation results of two employment growth models. In both models, the coefficient for spatially lagged dependent variable, $\rho$, was statistically significant, indicating the employment growth of MSA is affected by the growth of nearby MSAs.

Model 1 showed that the effect of diversity (Entropy) was statistically insignificant, indicating no significant influence of the overall industrial diversity level on employment growth.

The coefficients on COMP and EDUC showed expected signs. COMP was statistically significant at the 0.05 level, showing that the higher the level of competition, the higher the employment growth rate, which supports the theories of Jacobs [10] and Porter [30]. As expected, educational attainment also exerted a positive influence on the employment growth rates. Specifically, a one percentage point increase in population 25 years or older with at least a bachelor's degree was related to a 0.022 percentage point increase in employment growth rate. The population size variable, however, was found to be insignificant in explaining employment growth. 
Table 3. Estimation results of employment growth models.

\begin{tabular}{|c|c|c|c|c|c|}
\hline & & \multicolumn{2}{|c|}{ Model 1} & \multicolumn{2}{|c|}{ Model 2} \\
\hline & & Coefficient & $p$-Value & Coefficient & $p$-Value \\
\hline & Intercept & -0.973 & 0.330 & -0.725 & 0.468 \\
\hline \multirow{2}{*}{ Economic structure variables } & Entropy & -0.079 & 0.773 & -0.206 & 0.459 \\
\hline & MSI & - & - & 1.561 & 0.029 \\
\hline \multirow{3}{*}{ General control variables } & COMP & 0.670 & 0.001 & 0.483 & 0.032 \\
\hline & EDUC & 0.022 & 0.000 & 0.022 & 0.000 \\
\hline & POP & -0.038 & 0.321 & -0.029 & 0.449 \\
\hline \multirow{3}{*}{ Geographical dummies } & MW & 0.083 & 0.520 & 0.081 & 0.530 \\
\hline & NE & 0.457 & 0.001 & 0.455 & 0.001 \\
\hline & $\mathrm{S}$ & 0.383 & 0.000 & 0.374 & 0.000 \\
\hline \multirow{2}{*}{ Performance of individual sectors } & MANU & 0.130 & 0.000 & 0.124 & 0.000 \\
\hline & EDH & 0.173 & 0.000 & 0.171 & 0.000 \\
\hline \multirow{2}{*}{ Past performance } & PreEG & 0.187 & 0.000 & 0.189 & 0.000 \\
\hline & PreINSTAB & -0.001 & 0.851 & 0.000 & 1.000 \\
\hline $\operatorname{Rho}(\rho)^{1}$ & & 0.457 & 0.000 & 0.430 & 0.000 \\
\hline Pseudo R-squared & & \multicolumn{2}{|c|}{0.631} & \multicolumn{2}{|c|}{0.636} \\
\hline \multicolumn{2}{|l|}{ Number of Observations } & \multicolumn{4}{|c|}{353} \\
\hline
\end{tabular}

${ }^{1}$ Rho $(\rho)$ indicates spatially lagged dependent variable.

Regions differed significantly in employment growth rates. The dummy variables for both the Northeast and South regions were positive and significant at the 0.05 level, while that for the Midwest region was insignificant. Specifically, compared to the West, which was the omitted geographical dummy variable, during the study period, the employment of MSAs in the Northeast and South grew about 0.46 and 0.38 percentage points more per year respectively.

The growth rates of both the manufacturing and the education and health services sectors were positively and significantly associated with the employment growth rate. A one percentage point increase in the growth rate of the manufacturing and the education and health services sectors increases the employment growth rate by 0.13 and 0.17 percentage points, respectively.

Moreover, the employment growth in MSAs showed path dependency over time. The MSAs that had grown faster in the five years before the study period continued to grow faster during the period from 1998 to 2010. In contrast, past instability did not significantly affect the employment growth during the same period.

Model 2 was estimated with the MSI, the key industrial structure variable of this study. As expected, the coefficient of the MSI was positive and significant. This indicated that the MSAs with a higher proportion of specialized sectors grew faster during the study period. More specifically, one percentage point increase in the proportion of specialized sectors was associated with a 1.56 percentage point increase in the annual employment growth during the research period from 1998 to 2010.

Adding the MSI to the regression did not substantially change the parameter estimates and significance levels of the other independent variables. The estimation results of education attainment, performance of individual sectors, regional dummy variables and past economic performance showed quite similar patterns to the results of Model 1. Although the magnitude of effect dropped slightly, COMP still has a positive effect (significant at the 0.05 level) on the dependent variable. Like Model 1 , the Entropy index and initial population size variable had no significant association with the employment growth rate.

In addition, Models 3 and 4 in Table 4 also presented the estimation results of two wage growth models. As indicated in Table 4, the wage growth model yielded substantially similar results with the employment growth model, although the magnitudes of coefficients are all slightly changed. Specifically, a one percentage point increase in the ratio of specialized sectors was related with a 2.15 percentage point increase in the annual wage growth rate. 
Table 4. Estimation results of wage growth models.

\begin{tabular}{|c|c|c|c|c|c|}
\hline & & \multicolumn{2}{|c|}{ Model 1} & \multicolumn{2}{|c|}{ Model 2} \\
\hline & & Coefficient & $p$-Value & Coefficient & $p$-Value \\
\hline & Intercept & -0.698 & 0.626 & -0.273 & 0.849 \\
\hline \multirow{2}{*}{ Economic structure variables } & Entropy & -0.052 & 0.894 & -0.225 & 0.569 \\
\hline & MSI & - & - & 2.145 & 0.034 \\
\hline \multirow{3}{*}{ General control variables } & COMP & 0.956 & 0.001 & 0.699 & 0.028 \\
\hline & EDUC & 0.038 & 0.000 & 0.037 & 0.000 \\
\hline & POP & 0.013 & 0.806 & 0.026 & 0.629 \\
\hline \multirow{3}{*}{ Geographical dummies } & MW & 0.014 & 0.942 & 0.002 & 0.992 \\
\hline & NE & 0.481 & 0.013 & 0.474 & 0.014 \\
\hline & $\mathrm{S}$ & 0.638 & 0.000 & 0.624 & 0.000 \\
\hline \multirow{2}{*}{ Performance of individual sectors } & MANU & 0.187 & 0.000 & 0.180 & 0.000 \\
\hline & EDH & 0.162 & 0.000 & 0.159 & 0.000 \\
\hline \multirow{2}{*}{ Past performance } & PreEG & 0.219 & 0.000 & 0.223 & 0.000 \\
\hline & PreINSTAB & 0.020 & 0.851 & 0.023 & 0.831 \\
\hline $\operatorname{Rho}(\rho)^{1}$ & & 0.532 & 0.000 & 0.504 & 0.000 \\
\hline Pseudo R-squared & & \multicolumn{2}{|c|}{0.646} & \multicolumn{2}{|c|}{0.650} \\
\hline \multicolumn{2}{|l|}{ Number of Observations } & \multicolumn{4}{|c|}{353} \\
\hline
\end{tabular}

${ }^{1}$ Rho $(\rho)$ indicates spatially lagged dependent variable.

\subsection{Instability Models}

Similar to the growth models, two models-one with and the other without the MSI-were estimated for instability. Table 5 presents the results of the instability models with spatial lag. Also, the spatially-lagged dependent variable was statistically significant in both models 5 and 6, which implied that MSAs surrounded by unstable MSAs were likely to be unstable.

Table 5. Estimation results of employment instability models.

\begin{tabular}{|c|c|c|c|c|c|}
\hline & & \multicolumn{2}{|c|}{ Model 5} & \multicolumn{2}{|c|}{ Model 6} \\
\hline & & Coefficient & $p$-Value & Coefficient & $p$-Value \\
\hline & Intercept & -0.503 & 0.384 & -0.633 & 0.276 \\
\hline \multirow{2}{*}{ Economic structure variables } & Entropy & -0.437 & 0.002 & -0.382 & 0.007 \\
\hline & MSI & - & - & -0.627 & 0.083 \\
\hline \multirow{3}{*}{ General control variables } & COMP & 0.261 & 0.013 & 0.338 & 0.003 \\
\hline & EDUC & -0.007 & 0.003 & -0.007 & 0.003 \\
\hline & POP & 0.056 & 0.004 & 0.053 & 0.006 \\
\hline \multirow{3}{*}{ Geographical dummies } & MW & 0.028 & 0.658 & 0.018 & 0.772 \\
\hline & NE & 0.010 & 0.894 & 0.004 & 0.956 \\
\hline & $S$ & -0.012 & 0.821 & -0.013 & 0.805 \\
\hline \multirow{2}{*}{ Performance of individual sectors } & MANU & -0.015 & 0.027 & -0.012 & 0.079 \\
\hline & $\mathrm{EDH}$ & 0.038 & 0.007 & 0.039 & 0.005 \\
\hline \multirow{2}{*}{ Past performance } & PreEG & 0.092 & 0.000 & 0.092 & 0.000 \\
\hline & PreINSTAB & 0.109 & 0.004 & 0.108 & 0.005 \\
\hline $\operatorname{Rho}(\rho)^{1}$ & & 0.619 & 0.000 & 0.613 & 0.000 \\
\hline Pseudo R-squared & & \multicolumn{2}{|c|}{0.461} & \multicolumn{2}{|c|}{0.465} \\
\hline \multicolumn{2}{|c|}{ Number of Observations $^{2}$} & \multicolumn{4}{|c|}{352} \\
\hline
\end{tabular}

${ }^{1}$ Rho $(\rho)$ indicates spatially lagged dependent variable; ${ }^{2}$ Because both instability models 5 and 6 indicate one influential case, Punta Gorda, FL (Fips:39460), that non-intuitively skewed the estimation results of structural variables, the estimation results without this influential case are reported in the above table. 
In Model 5, the Entropy index showed a negative and significant association with employment instability in MSAs during the study period from 1998 to 2010. This means that the MSAs with a higher level of industrial diversity were more stable in employment growth during this study period. This result was consistent with the theoretical expectation and empirical findings from many previous studies.

All the general control variables-competition, educational attainment and population size- turned out to be significant. We found that the higher the competition in an MSA, the higher its employment instability. This finding is consistent with that from a previous study by Gaspar and Massa [52]. The MSAs with higher educational attainment experienced less employment instability. Because the initial population size was logged, the coefficient on the POP can be interpreted as elasticity. The estimated elasticity of instability with respect to initial population size was 0.056 , which indicated that a one percent increase in the population size increased the employment instability indicator by about 0.06 percent.

All the coefficients on the geographic dummy variables were insignificant. This implied that geographic location was not a significant factor to affect the employment instability of MSAs.

Performance of individual sectors had a significant influence on employment instability. The average annual growth rate of manufacturing $(M A N U)$, the sector with the fastest decline, was negatively associated with instability and this association was significant at the 0.05 level. A one percentage point increase in manufacturing growth led to a 1.5 percent decrease in the instability indicator. Because manufacturing has been on the trajectory of long-run decline since the 1980s, the result can be interpreted as indicating that the lower speed of decline of the manufacturing sector contributed to the economic stability. In contrast, the average annual growth rate of the education and health services sector $(E D H)$ was positively associated with employment instability. Specifically, a one percentage point increase in the growth rate of the education and health services sector increased the instability indicator by about 3.8 percent. Because the education and health services sector grew the most during the overall time period, this high growth probably brought instability to the overall employment growth.

Similar to growth, employment instability in MSAs also showed path dependency. The MSAs that had experienced a higher instability in the five years prior to 1998 continued to show a higher level of instability from 1998 to 2010. Moreover, past employment growth was also positively and significantly associated with the current employment instability. This result reflects a tendency that the regions that had experienced higher growth rates during the 1990s (e.g., Las Vegas, NV and Prescott, AZ) also underwent more instable economic situations during this study period. Specifically, a one percentage point increase in the path employment growth rate was related to a 9.2 percent increase in instability from 1998 to 2010.

Model 6 is the instability model estimated with the MSI included as one of the independent variables. The results showed that the MSI was significantly and negatively associated with employment instability. The $p$-value for the MSI is about 0.042 under a one-tailed test, which was statistically significant at the 0.05 level. In other words, regional economies with higher percentages of specialized sectors were more likely to see stable economic growth.

The estimation results for other explanatory variables were substantially the same as those in Model 3, except for some slight differences in the magnitude of effects. Diversity (Entropy) and education attainment (EDUC) still showed strong negative associations with instability while competition $(C O M P)$, population size $(P O P)$ and the growth rate of education and health service sector $(E D H)$ showed positive association. All the geographical dummy variables were still insignificant.

\section{Conclusions}

In this study, an indicator (MSI) was constructed to measure the extent of multiple specializations in regional economy. This new indicator differs from the commonly-used industrial structure indicators 
such as the Herfindahl and Entropy indexes that measure the extent of overall specialization or diversity in the economy.

This new indicator was applied to study how industrial structure affected the economic performance of MSAs in the U.S. from 1998-2010. The empirical results showed that the MSI positively correlated with both economic growth and stability. Regions with diversified specializations were more likely to experience both higher employment growth rates and less turbulence in employment growth at the same time compared with those with fewer specializations.

In contrast, overall diversity in the economic structure, measured by the Entropy index, was found to contribute significantly only to economic stability but not to economic growth in the MSAs during the study period. Fostering economic diversity might help regional economies weather internal and external shocks but not necessarily help them grow faster.

One of the advantages of dealing with both economic growth and stability is to obtain the policy implications for enhancing the sustainability of regional economic development [57]. Considering economic (in)stability is measured based on the deviation from a long-term growth path, the strategies promoting economic stability might be very helpful for regions to sustain their economic growth path. Specifically, through the reinforcement in both growth and stability, the strategy of increasing the number of specialized sectors is more likely to positively affect the sustainability of regional economic performance. Thus, there are several implications for sustainable economic development policy. In the traditional view, specialization and diversification were treated as policies in opposite directions. As Wagner and Deller [11] pointed out, because economic instability can be aggravated by specialization, it can be difficult for policymakers to pursue a course between the two contradictory goals of economic growth and stability. This study shows that this policy dilemma can be reconciled. Through empirical analysis, it was shown that growth and stability are not contradictory goals. Policymakers can attempt to pursue both growth and stability simultaneously by shifting from simple diversification or simple specialization to developing multiple specializations. Building industrial clusters in an economy can be the strategy because the comparative advantages of economic specialization can drive economic growth in regions [4]. While doing so, regions should spread their investments to build or develop clusters in diversified industrial sectors.

If some regions already have a certain level of diversity in their economic structure, the local governments for those regions can select several potential sectors and enhance these sectors by promoting niche creation from existing industries [58]. However, if the economies of regions already suffer from a lack of diversity, the local governments should promote both diversity and specialization together. As explained by Desrochers and Sautet [59], the diversified economic structure can work as a necessary precondition or foundation for multiple specializations in regions. Moreover, Malizia and Feser [4] (p. 92) argued that "economic diversity can only be defined operationally as the presence of multiple specializations." In this sense, diversification should be processed based on the full consideration of specialization. So rather than spending a great deal of a budget to import "advanced sectors" or "popular sectors", the local governments should focus instead on recruiting the sectors that have many linkages with the indigenous comparative advantages in their regions. By connecting the imported sectors with these indigenous strengths, the locality can develop multiple specializations much more efficiently than relentlessly attracting and developing a brand-new sector.

There are a few directions for future research. The findings in this study were based on MSA-level data from 1998 to 2010. By extending the research time span and comparing the various different time periods, the results can be enriched. This research can also be extended by studying different geographic scales. Moreover, this study did not specify any shock that may destabilize the regional economy. A future direction is to examine how industrial structure affects the ability of a regional economy to respond to specific shocks, such as an economic recession or a natural disaster. 
Author Contributions: Saheum Hong conducted the research design and econometric analysis, and drafted the manuscript. Yu Xiao conducted literature review and reviewed the analytical results and provided extensive revision. Both authors wrote, read, and approved the final manuscript.

Conflicts of Interest: The authors declare no conflict of interest.

\section{References}

1. Chinitz, B. Contrasts in agglomeration: New York and Pittsburgh. Am. Econ. Rev. 1961, 51, $279-289$.

2. Beaudry, C.; Schiffauerova, A. Who's right, Marshall or Jacobs? The localization versus urbanization debate. Res. Policy 2009, 38, 318-337. [CrossRef]

3. Glaeser, E.L.; Kallal, H.D.; Scheinkman, J.A.; Shleifer, A. Growth in cities. J. Political Econ. 1992, 100, 1126-1152. [CrossRef]

4. Malizia, E.; Feser, E.J. Understanding Local Economic Development; Center for Urban Policy Research: New Brunswick, NJ, USA, 1999.

5. Quigley, J.M. Urban diversity and economic growth. J. Econ. Lit. 1998, 12, 127-138. [CrossRef]

6. Richardson, H.W. Regional Economics; Praeger: New York, NY, USA, 1969.

7. Siegel, P.B.; Alwang, J.; Johnson, T.G. A structural decomposition of regional economic instability: A conceptual framework. J. Reg. Sci. 1995, 35, 457-470. [CrossRef]

8. Marshall, A. Principles of Economics; Macmillan: London, UK, 1890.

9. Fujita, M.; Thisse, J. Economics of Agglomeration: Cities, Industrial Location and Regional Growth; Cambridge University Press: Cambridge, UK, 2002.

10. Jacobs, J. The Economy of Cities; Vintage Books: New York, NY, USA, 1969.

11. Wagner, J.E.; Deller, S.C. Measuring the effects of economic diversity on growth and stability. Land Econ. 1998, 74, 541-556. [CrossRef]

12. Henderson, J.V.; Kuncoro, A.; Turner, M. Industrial development in cities. J. Political Econ. 1995, 103, 1067-1090. [CrossRef]

13. Kemeny, T.; Storper, M. Is specialization good for regional economic development? Reg. Stud. 2015, 49, 1003-1018.

14. Rosenthal, S.; Strange, W. Geography, industrial organization, and agglomeration. Rev. Econ. Stat. 2003, 85, 377-393. [CrossRef]

15. Shuai, X. Will specialization continue forever? A case study of interactions between industry specialization and diversity. Ann. Reg. Sci. 2013, 50, 1-24. [CrossRef]

16. Storper, M. Why does a city grow? Specialisation, human capital or institutions? Urban Stud. 2010, 47, 2027-2050. [CrossRef]

17. Attaran, M.; Zwick, M. Entropy and other measures of industrial diversification. Q. J. Bus. Econ. 1987, 26, $17-34$.

18. Barth, J.; Kraft, J.; Wiest, P. A portfolio theoretic approach to industrial diversification and regional employment. J. Reg. Sci. 1975, 15, 9-15. [CrossRef]

19. Kort, J.R. Regional economic instability and industrial diversification in the US. Land Econ. 1981, 57, 596-608. [CrossRef]

20. Malizia, E.; Ke, S. The influence of economic diversity on unemployment and stability. J. Reg. Sci. 1993, 33, 221-235. [CrossRef]

21. Smith, S.M.; Gibson, C.M. Industrial diversification in nonmetropolitan counties and its effect on economic stability. West. J. Agric. Econ. 1988, 13, 193-201.

22. Trendle, B. Regional economic instability: The role of industrial diversification and spatial spillovers. Ann. Reg. Sci. 2006, 40, 767-778. [CrossRef]

23. Attaran, M. Industrial diversity and economic performance in US areas. Ann. Reg. Sci. 1986, 20, 44-54. [CrossRef]

24. Drucker, J. Regional industrial structure concentration in the United States: Trends and implications. Econ. Geogr. 2011, 87, 421-452. [CrossRef]

25. Izraeli, O.; Murphy, K.J. The effect of industrial diversity on state unemployment rate and per capita income. Ann. Reg. Sci. 2003, 37, 1-14. [CrossRef] 
26. Badenhausen, K. While Rest of U.S. Economy Plods, Houston Gets Hot. Available online: http:/ / www.forbes. com/sites\#/sites/kurtbadenhausen/2012/06/27/houstons-business-climate-heats-up/\#3da53cc01469 (accessed on 21 July 2014).

27. The 2014 Economic Impact of Marine Cargo Activity at the Port of Houston on the State of Texas and the United States. Available online: http://www.portofhouston.com/static/gen/about-us/Misc/National_ Economic_Impact_Report_2015.pdf (accessed on 2 May 2015).

28. Arrow, K.J. The economic implications of learning by doing. Rev. Econ. Stud. 1962, 29, 155-173. [CrossRef]

29. Romer, P.M. Increasing returns and long-run growth. J. Political Econ. 1986, 94, 1002-1037. [CrossRef]

30. Porter, M.E. The Competitive Advantage of Nations; Macmillan: New York, NY, USA, 1990.

31. Saxenian, A. Regional Advantage: Culture and Competition in Silicon Valley and Route 128; Harvard University Press: Cambridge, MA, USA, 1994.

32. Cingano, F.; Schivardi, F. Identifying the sources of local productivity growth. J. Eur. Econ. Assoc. 2004, 2, 720-744. [CrossRef]

33. Combes, P.P. Economic structure and local growth: France, 1984-1993. J. Urban Econ. 2000, 47, 329-355. [CrossRef]

34. Drennan, M.; Larsen, S.; Lobo, J.; Strumsky, D.; Utomo, W. Sectoral shares, specialization and metropolitan wages in the United States, 1969-96. Urban Stud. 2002, 39, 1129-1142. [CrossRef]

35. Youn, H.; Bettencourt, L.M.; Lobo, J.; Strumsky, D.; Samaniego, H.; West, G.B. Scaling and universality in urban economic diversification. J. R. Soc. Interface 2016, 13, 20150937. [CrossRef] [PubMed]

36. McLaughlin, G.E. Industrial diversification in American cities. Q. J. Econ. 1930, 45, 131-149. [CrossRef]

37. Lynch, L.K. Economic structure and economic performance: Some evidence for states. J. Reg. Anal. Policy 1979, 9, 84-95.

38. Brewer, H.; Moomaw, R.L. A note on population size, industrial diversification, and regional economic instability. Urban Stud. 1985, 22, 349-354. [CrossRef]

39. Jackson, R.W. An evaluation of alternative measures of regional industrial diversification. Reg. Stud. 1984, 18, 103-112. [CrossRef]

40. Wasylenko, M.J.; Erickson, R.A. “On measuring economic diversification”: Comment. Land Econ. 1978, 54, 106-109. [CrossRef]

41. Garmestani, A.; Allen, C.; Mittelstaedt, J.; Stow, C.; Ward, W. Firm size diversity, functional richness, and resilience. Environ. Dev. Econ. 2006, 4, 533-551. [CrossRef]

42. Sherwood-Call, C. Assessing regional economic stability: A portfolio approach. Econ. Rev. 1990, 1, 17-26.

43. Gilchrist, D.A.; St. Louis, L.V. Directions for diversification with an application to Saskatchewan. J. Reg. Sci. 1991, 31, 273-289. [CrossRef]

44. Farhauer, O.; Kröll, A. Diversified specialisation-Going one step beyond regional economics' specialisation-diversification concept. Jahrb. Reg. Wiss. 2012, 32, 63-84. [CrossRef]

45. Aiginger, K.; Davies, S.W. Industrial specialization and geographic concentration: Two sides of the same coin? Not for the European union. J. Appl. Econ. 2004, 7, 231-248.

46. Theil, H.; Finizza, A.J. A note on the measurement of racial integration of schools by means of informational concepts. J. Math. Soc. 1971, 1, 187-193. [CrossRef]

47. Herfindahl, O.C. Concentration in the Steel Industry. Unpulished Ph.D. Thesis, Columbia University, New York, NY, USA, 1950.

48. Hirschman, A.O. The paternity of an index. Am. Econ. Rev. 1964, 54, 761-762.

49. Scherer, F.M.; Ross, D. Industrial Market Structure and Economic Performance; Houghton Mifflin: Boston, MA, USA, 1990.

50. Mizuno, K.; Mizutani, F.; Nakayama, N. Industrial diversity and metropolitan unemployment rate. Ann. Reg. Sci. 2006, 40, 157-172. [CrossRef]

51. Ejermo, O. Technological diversity and Jacobs' externality hypothesis revisited. Growth Chang. 2005, 36, 167-195. [CrossRef]

52. Gaspar, J.M.; Massa, M. Idiosyncratic Volatility and Product Market Competition. J. Bus. 2006, 79, 3125-3152. [CrossRef]

53. Cutler, A.T.; Hansz, J.E. Sensitivity of cities to economic fluctuations. Growth Chang. 1971, 2, 23-28. [CrossRef]

54. Lucas, R.E. On the mechanics of economic development. J. Monet. Econ. 1988, 22, 3-42. [CrossRef]

55. Krugman, P. First nature, second nature, and metropolitan location. J. Reg. Sci. 1993, 33, 129-144. [CrossRef] 
56. Carlino, G.A.; Mills, E.S. The determinants of county growth. J. Reg. Sci. 1987, 27, 39-54. [CrossRef] [PubMed]

57. Ioppolo, G.; Cucurachi, S.; Salomone, R.; Saija, G.; Shi, L. Sustainable Local Development and Environmental Governance: A Strategic Planning Experience. Sustainability 2016, 8, 180. [CrossRef]

58. Frenken, K.; van Oort, F.; Verburg, T. Related variety, unrelated variety and regional economic growth. Reg. Stud. 2007, 41, 685-697. [CrossRef]

59. Desrochers, P.; Sautet, F. Entrepreneurial policy: The case of regional specialization vs. spontaneous industrial diversity. Entrep. Theory Pract. 2008, 32, 813-832. [CrossRef]

(C) 2016 by the authors; licensee MDPI, Basel, Switzerland. This article is an open access article distributed under the terms and conditions of the Creative Commons Attribution (CC-BY) license (http://creativecommons.org/licenses/by/4.0/). 